\title{
Apresentado na I Jornada Científica do Esporte Coletivo Recife - PE, 2018. MONITORAMENTO ELETRÔNICO NO FUTEBOL PROFISSIONAL - ASPECTOS DO TREINAMENTO
}

\section{Professor Esp. Clovis Calado.}

No Futebol existem vários fatores multidisciplinares que são diretamente relacionados com o rendimento. De acordo com os princípios básicos do treinamento desportivo de alto rendimento, para poder prescrever uma seção de treinamento, a condição fundamental é saber se a ênfase será em volume ou em intensidade, bem como se a qualidade/quantidade dos estímulos a serem empregados é adequada. Existe a necessidade de se estabelecerem parâmetros, com os quais devem ser criados os ciclos/cargas do treino a serem aplicadas. $O$ principal referencial pelo qual todo e qualquer planejamento no Futebol se baseia, é o JOGO. Pois, trata-se de um conjunto de ações físicas, técnicas, táticas individuais e coletivas, complexas, que irão direcionar todos os treinamentos. Nos dias atuais, a tecnologia proporcionou um avanço significativo relacionado ao registro e controle dessas ações, durante jogos e/ou treinamentos. A existência de softwares que possibilitam este monitoramento propicia estabelecer referências de volumes/intensidades em tempo real, que durante os treinamentos/jogos, através de variáveis importantes como distância, velocidade, freqüência cardíaca, etc., mapeando-se os atletas e coletando dados, para que sejam estabelecidos protocolos que indicarão, por sua vez, a identificação da capacidade física a ser treinada. Com o objetivo de determinar quando e em que momento os ajustes poderão ser efetuados para conseguir a homogeneidade do rendimento pretendido durante os jogos e/ou seção de treinamento. As intervenções servirão ainda, qualificando o treino/jogo, no aspecto físico e no aspecto tático, pois além de toda a quantificação através da perfeita execução dos parâmetros citados, para servir também, como fator comparativo em atletas de uma mesma posição, para se definir um padrão de movimentos/ações individuais e coletivas.

Palavras-chave: Futebol, Monitoramento, Treinamento.

Email: cloviscaladoccpm@@gmail.com 